Report

\title{
Distribution of Ha-RAS-1 proto-oncogene alleles in breast cancer patients and in a control population
}

Giuseppe Saglio, Clara Camaschella, Maurizia Giai, Anna Serra, Angelo Guerrasio, Bruno Peirone, Paolo Gasparini, Umberto Mazza, Ruggero Ceppellini, Nicoletta Biglia, Paolo Cortese and Piero Sismondi Dipartimento di Scienze Biomediche e Oncologia Umana, Sezione Clinica, Universitá di Torino, Italy; CNR, Centro di Immunogenetica e Istocompatibilitá, Torino, Italy; Istituto di Ginecologia e Ostetricia dell'Universitá di Torino, Italy

Key words: alleles, Ha-ras, oncogenes, RFLP's

\section{Summary}

The frequencies of 13 different Ha-ras proto-oncogene alleles have been estimated in 92 breast cancer patients and 60 unaffected individuals. The Ha-ras alleles can be identified using a DNA restriction fragment length polymorphism (RFLP) closely linked to the $3^{\prime}$ end of the gene, and are characterized by a different length due to a region of sequences repeated a variable number of times (variable tandem repeats, VTR).

The statistical analysis of the data obtained shows that the frequency of alleles ranging between specific length limits is significantly higher in breast cancer patients than in controls. The same applies to specific genotypes bearing the aforementioned alleles. This suggests that the inheritance of these alleles may be associated with an increased risk of developing breast cancer.

\section{Introduction}

Ha-ras is a proto-oncogene whose activation has been estimated to occur in about 10 to $15 \%$ of primary solid tumors [1.]. Coding sequence mutations, causing amino acid substitutions at critical positions within the $\mathrm{p} 21$ product, as well as truncation of a putative $5^{\prime}$ exon, have been reported to represent critical steps in the Ha-ras activation process [2-6]. Recent microinjection experiments have also demonstrated that overdosage of the normal Ha-ras product may be sufficient to induce cell transformation [7] and, with respect to normal tissues, increased amounts of $\mathrm{p} 21$ have been found in tumor cells of primary breast carcinomas and have been shown to correlate with other clinical and prognostic variables $[8,9]$.
These circumstances, and others as well, greatly support the hypothesis of an involvement of the Ha-ras proto-oncogene in tumorigenesis, although its precise role in this process still remains to be defined [10].

The Ha-ras gene is characterized by the presence of a closely linked restriction fragment length polymorphism (RFLP), due to the presence of a 28 nucleotide sequence that can be repeated a variable number of times [11]. This variable tandem repeat (VTR) region is located about $1 \mathrm{~kb}$ downstream from the $3^{\prime}$ end of the gene (Fig. 1). Using a probe for this region, several allelic fragments of different size, which define a corresponding number of Ha-ras alleles, can be identified by Southern blotting analysis.

Studies investigating whether the presence of 
human Ha-ras

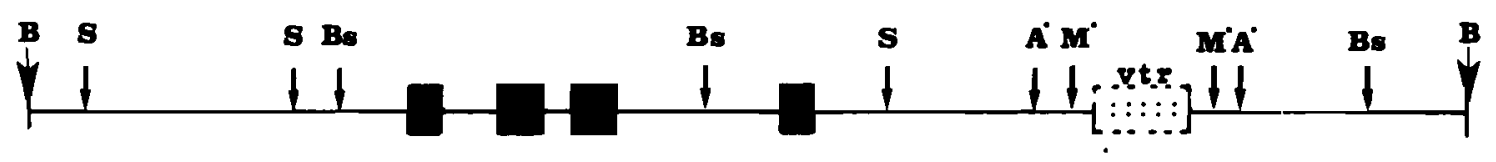

\section{$1 \mathbf{K B}$}

Fig. 1. Restriction map of the human Ha-ras proto-oncogene; $\mathrm{B}=\mathrm{Bam} \mathrm{HI}, \mathrm{S}=\mathrm{Sst} \mathrm{I}$, Bs $=$ Bst EII, A = Ava II, M = Msp I, C = Cla I. The black boxes represent exons, the open box the VTR region. Only the Ava II and Msp I sites (marked by asterisks) immediately flanking the VTR region have been included in the map.

some Ha-ras alleles may be associated with an increased risk of developing cancer have reached controversial results. Whereas different frequencies of specific $\mathrm{Ha}$-ras alleles were initially reported in neoplastic and normal DNAs of cancer patients compared to normal subjects [12], subsequent studies performed on patients affected by specific tumors failed to find significant associations [13, 14]. Recently, however, Lidereau et al. [15], studying a large series of tumor and peripheral blood DNA samples obtained from breast cancer patients, observed a high frequency of rare Ha-ras alleles compared to a control population. As this observation, if confirmed, would have major implications for assessing the individual risk to breast cancer susceptibility, we found it interesting to analyze the Ha-ras polymorphism distribution between breast cancer patients and controls in another ethnic group. Moreover, as modifications of some polymorphisms present on the short arm of chromosome 11 have been reported to occur frequently in breast cancer tumor tissue $(27 \%$ of the cases) [16] as well as in other tumors compared to the germ-line pattern visible in the peripheral blood DNA, we have performed our study exclusively on leucocyte DNA samples.

\section{Materials and methods}

Peripheral blood samples of 92 breast cancer patients and of 60 controls have been examined.

Controls were individuals of both sexes, more than 35 years old and known to be unaffected by cancer.

Patients were women with breast cancer admitted for treatment or already operated upon and regularly followed-up at the Gynecologic Oncology Department of the University of Torino. Patients median age was 54 years (range 28-78). Histopathology was: in situ lobular carcinoma 3, infiltrating ductal carcinoma 64 , lobular 17 , medullary 4 , papillary 1 , tubular 3 . At the time of diagnosis, 49 patients were at stage I, 31 at stage II, 9 at stage III, 3 at stage IV. At the time of blood sampling, all the patients were out of treatment, but 42 had received previous adjuvant locoregional radiotherapy ( $5000 \mathrm{cGy})$ and 32 had received previous cytotoxic chemotherapy (CMF, 18).

DNA was obtained from peripheral blood leucocytes by phenol-chloroform extraction. The samples were digested with $5 \mathrm{U} / \mu \mathrm{g}$ of AvaII endonuclease according to manufacturer's specifications, run on $0.8 \%$ agarose gel, and transferred to nitrocellulose membrane by Southern blotting [19]. Prehybridization $(12 \mathrm{hr})$ and hybridization $(18-20 \mathrm{hr})$ 


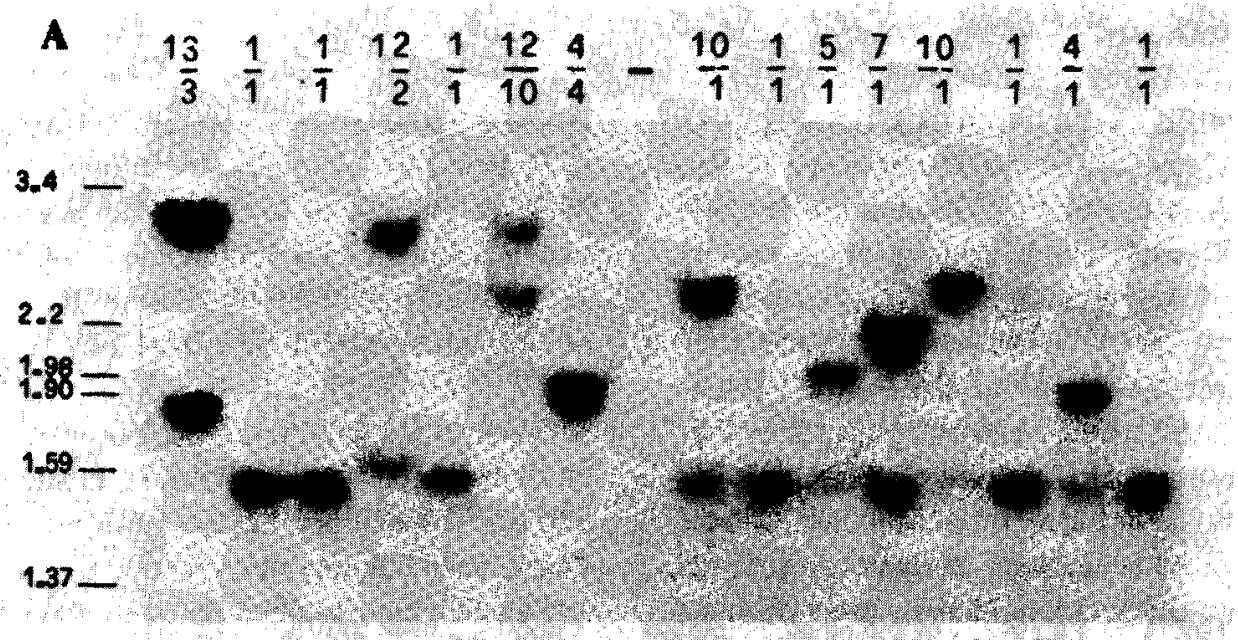
$1234567-89101112131415$

B $\quad \frac{10}{1} \frac{10}{1} \frac{1}{1} \quad \frac{4}{1} \frac{4}{1} \quad \frac{5}{1} \quad 4 \quad 8 \quad 12, \frac{1}{1} \frac{1}{1} \frac{12}{1} 1 \frac{2}{1}$

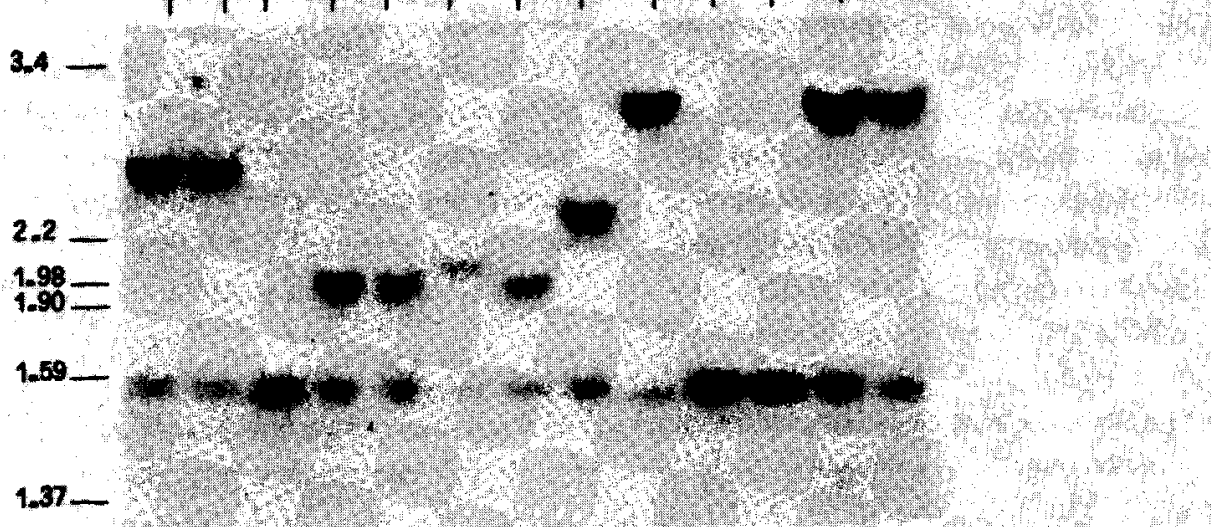

\section{3}

Fig. 2. Southern blotting analysis showing VTR alleles of different length; the number on the top of each lane refers to the rank number on Table 1. Lanes 1-10 in gel A and lanes 1-7 in gel B contain DNA samples from breast cancer patients; lanes 11-15 in gel A and 8-13 in gel $B$ are from normal controls. The restriction enzyme used for both gels was Ava II. The molecular weight markers on the side of each gel represent the positions of fragment of known length derived by digesting lambda phage DNA simultaneously with EcoRI and Hind III.

procedures were performed at $42^{\circ} \mathrm{C}$ in a $6 \mathrm{X} \mathrm{SSC}$, $0.5 \%$ SDS, 5 X Denhart's solution ( $1 \%$ Ficoll, $1 \%$ PVP, $1 \%$ BSA), containing $200 \mu \mathrm{g} / \mathrm{ml}$ of salmon sperm DNA and $50 \%$ formamide.

The hybridization probe was a $6.4 \mathrm{~kb}$ BamHI fragment corresponding to the entire Ha-ras gene and to 3 ' flanking sequences including the VTR region [20]. The probe was nick-translated to a specific activity of $1 \times 10^{8} \mathrm{cpm} / \mu \mathrm{g}$. After hybridization, the filters were initially washed twice in $2 \mathrm{X}$ SSC, $0.1 \%$ SDS for $20 \mathrm{~min}$ at room temperature and then twice in $0.1 \mathrm{X} \mathrm{SSC}, 0.1 \% \mathrm{SDS}$ at $52^{\circ} \mathrm{C}$ for $30 \mathrm{~min}$. The dried filters were subsequently exposed to X-ray films for various periods of time at $-80^{\circ} \mathrm{C}$.

The allelic VTR fragments defining the Ha-ras 
alleles have been identified by different authors [12-16] using different restriction enzymes (BamHI, MspI, Avall). As in our hands BamHI gave unsatisfactory results in terms of resolution of the different bands, according to Thein et al. [13], we decided to use Avall, which produces fragments of smaller molecular size and therefore allows a better discrimination (Fig. 2). Nevertheless, it was sometimes difficult to compare the size of the Ha-ras alleles between different gels; we then ran gels with control DNA samples containing similar sized alleles. However, in our experimental conditions, a degree of microheterogeneity of less than $0.05 \mathrm{~kb}$ cannot be reasonably distinguished, even running control DNA samples in adjacent tracks.

Statistical significance of proportion differences was calculated by the Chi Square method with Yates' correction. Fisher's exact test was used when one or more of the expected values was less than 5; 95\% confidence limits are reported for the odds ratio.

'Common' alleles were defined as those alleles whose frequency in normal population is above the median. For statistical analysis, classes with frequency $<0.8$ have been pooled with alleles of similar size as indicated by small letters in Table 1.

\section{Results}

Among patients and controls considered together (152 cases) we were able to recognize 13 different VTR fragments of a molecular size ranging between 1.5 and $3.2 \mathrm{~kb}$, and we ranked them from 1 to 13. According to the aforementioned criteria we defined as 'common' the alleles of 1.50, 3.10, 2.70, and $2.40 \mathrm{~kb}$ (Table 2).

As expected for alleles, no more than two different fragments were observed in a single individual and the absence of fragments was never observed. These data suggest the absence of 'blank' alleles and justify the direct count of the alleles from the RFLP genotypes.

The distribution of alleles and genotypes found in patients and controls are reported in Tables 1 and 2. The distribution of rare alleles is significantly different in cases and in controls $(\mathrm{p}=0.0002) ; 34$ rare alleles are found out of 92 breast cancer $\mathrm{pa}$ tients and only 4 are found out of 60 controls. The most striking result is that alleles with molecular size between 1.80 and $2.20 \mathrm{~kb}$ are present 31 times in patients and only once in controls; this difference is highly significant $(\mathrm{p}<0.0001)$.

Considering each single allele, the $2.00 \mathrm{~kb}$ allele

Table 1. Comparison of VTR alleles directly counted from observed RFLP genotypes among breast cancer patients and controls.

\begin{tabular}{|c|c|c|c|c|c|}
\hline \multirow[t]{2}{*}{ Rank } & \multirow{2}{*}{$\begin{array}{l}\text { Alleles } \\
\text { Size }(\mathbf{k b})\end{array}$} & \multicolumn{2}{|c|}{ Patients } & \multicolumn{2}{|c|}{ Controls } \\
\hline & & n. & $\%$ & n. & $\%$ \\
\hline 1 & 1.50 & 108 & 58.12 & 78 & 65.00 \\
\hline 2 & 1.60 & 7 & 3.80 & 4 & 3.33 \\
\hline 3 & 1.80 & 5 & 2.72 & 0 & $-\quad(p=0.17)$ \\
\hline 4 & 2.00 & 20 & 10.86 & 1 & $0.83(\mathrm{p}=0.016)$ \\
\hline 5 & 2.10 & 4 & 2.17 & 0 & - \\
\hline 6 & 2.20 & 2 & 1.09 & 0 & 0 \\
\hline 7 & 2.40 & 0 & - & 5 & $4.58(p=0.02)$ \\
\hline $8^{a}$ & 2.55 & 0 & - & 1 & 0.83 \\
\hline $9^{\mathrm{a}}$ & 2.60 & 1 & 0.54 & 1 & 0.83 \\
\hline 10 & 2.70 & 18 & 9.78 & 12 & 10.00 \\
\hline 11 & 2.80 & 1 & 0.54 & 1 & 0.83 \\
\hline 12 & 3.10 & 17 & 9.24 & 17 & 14.17 \\
\hline 13 & 3.20 & 1 & 1.08 & 0 & - \\
\hline Tot. & & 184 & 100.00 & 120 & 100.00 \\
\hline
\end{tabular}

${ }^{a}$ For analysis, classes with expectation $<0.8$ have been pooled with alleles of similar size as indicated by small letters. 
(\#4), is significantly more frequent in patients than in controls $(p<0.01)$, whereas the $2.40 \mathrm{~kb}$ allele (\#7), is significantly more frequent in controls than in patients $(\mathrm{p}<0.01)$. For the other alleles no significant distribution differences have been found.

Coming to the comparison of the VTR genotypes, the only significant difference is observed for the genotype $1 / 4(10 / 92$ vs. $1 / 60 ; p<0.028)$. If we compare patients and controls bearing at least one allele \#4 the difference becomes more prominent $(16 / 76$ vs. $1 / 59 ; p<0.006)$. It is therefore appropriate to calculate the relative risk of developing cancer in carriers of allele \# 4 versus all other genotypes [21]. The odds ratio between patients and

Table 2. Comparison of the VTR genotypes observed among breast cancer patients and controls.

\begin{tabular}{|c|c|c|c|c|}
\hline \multirow{2}{*}{$\begin{array}{l}\text { Geno- } \\
\text { types }\end{array}$} & \multicolumn{2}{|c|}{ Patients } & \multicolumn{2}{|c|}{ Controls } \\
\hline & no. & $\%$ & No. & $\%$ \\
\hline $1 / 1$ & 33 & 35.87 & 24 & 40 \\
\hline $1 / 2$ & 2 & 2.17 & 2 & 3.33 \\
\hline $1 / 3$ & 3 & 3.26 & 0 & - \\
\hline $1 / 4$ & 10 & 10.87 & 1 & $\begin{array}{c}1.67 \\
(p=0.03)\end{array}$ \\
\hline $1 / 5$ & 4 & 4.35 & 0 & - \\
\hline $1 / 7$ & 0 & - & 3 & 5.00 \\
\hline $1 / 8$ & 0 & - & 1 & 1.67 \\
\hline $1 / 9$ & 1 & 1.09 & 1 & 1.67 \\
\hline $1 / 10$ & 11 & 11.96 & 8 & 13.33 \\
\hline $1 / 11$ & 0 & 0 & 1 & 1.67 \\
\hline $1 / 12$ & 11 & 11.96 & 13 & 21.67 \\
\hline $2 / 3$ & 1 & 1.09 & 0 & - \\
\hline $2 / 4$ & 1 & 1.09 & 0 & - \\
\hline $2 / 6$ & 1 & 1.09 & 0 & - \\
\hline $2 / 10$ & 0 & - & 1 & 1.67 \\
\hline $2 / 12$ & 2 & 2.17 & 1 & 1.67 \\
\hline $3 / 13$ & 1 & 1.09 & 0 & - \\
\hline $4 / 4$ & 4 & 4.35 & 0 & - \\
\hline $4 / 11$ & 1 & 1.09 & 0 & - \\
\hline $6 / 10$ & 1 & 1.09 & 0 & - \\
\hline $7 / 10$ & 0 & - & 1 & 1.67 \\
\hline $10 / 10$ & 1 & 1.09 & 0 & - \\
\hline \multirow[t]{2}{*}{$10 / 12$} & 4 & 4.35 & 3 & 5.00 \\
\hline & 92 & 100.00 & 60 & 100.00 \\
\hline
\end{tabular}

a The different fragments (alleles) have been indicated with the ranks reported in Table 1 . Genotypes absent in the two populations have been omitted. controls for genotypes containing at least one allele \#4 is 12.04 (95\% confidence limits: 1.65 to 75.1 ).

\section{Discussion}

Our data suggest a positive association between an increased risk of breast cancer and the presence of specific Ha-ras alleles and genotypes.

The use of different restriction enzymes and the small differences in size of the various VTR fragments make a comparison between the data obtained by different groups difficult. Our results however seem to confirm, on peripheral blood DNAs of a large series of breast cancer patients, the results obtained by Lidereau et al. [15] on a mixed series of DNAs extracted from leucocytes and tumor specimens.

If subjects carrying specific Ha-ras alleles have a higher susceptibility to breast cancer, an inheritable component must be present. This, however, may be feeble because of incomplete penetrance and need of interaction with other internal or environmental factors. In such circumstances, the presence of such a component may be difficult to demonstrate and requires studies on families with large genealogic trees. Moreover, a different pattern of methylation of the VTR region at the $3^{\prime}$ end of the Ha-ras proto-oncogene has recently been demonstrated for alleles of maternal or paternal origin [22] and, as the methylation pattern may influence gene expression and therefore the penetrance of the different alleles, this may further complicate the analysis.

At present the reasons for differences in the VTR sizes to correlate with a higher risk for breast cancer is difficult to perceive. In our opinion it is hard to conceive that some specific Ha-ras alleles should undergo, more easily than others, the mutations that have been described to activate the Haras oncogenic potential. It is more likely that other unknown differences, within the Ha-ras region and in linkage disequilibrium with the VTR polymorphism, may account for an increased risk of disease.

An explanation might originate from recent data which suggest a functional role of the VTR region 
itself. Ishii et al. [23] have reported that the VTR's act as enhancer elements on the Ha-ras gene transcription, and this activity appears to vary according to the VTR length. As already reported, overdosage of the normal Ha-ras $\mathrm{p} 21$ protein has been shown to be able to cause cell transformation [7]. It is therefore conceivable that cells bearing Ha-ras alleles allowing a higher level of gene transcription could be more susceptible than others to neoplastic transformation. At present the analysis of the correlation between the length of the VTRs studied by Ishii and co-workers and the naturally existing $\mathrm{Ha}$ ras alleles is not possible, but studies are in progress to test this hypothesis.

\section{Acknowledgements}

This work has been supported by A.I.R.C. (Associazione Italiana per la Ricerca sul Cancro) and by CNR- Rome, P.F. 'Oncologia', grant no. 86.00720.44. We thank Dr. S.R. Tronick and Dr. S.A. Aaronson for the gift of the probe used in this study.

\section{References}

1. Pulciani S, Santos E, Lauver AV, Long LK, Aaronson SA, Barbacid M: Oncogenes in solid human tumors. Nature 300: 539-542, 1982

2. Tabin CJ, Bradley SM, Bargmann CI, Weinberg RA, Papageorge AG, Scolnick EM, Dhar R, Lowy DR, Chang EH: Mechanism of activation of a human oncogene. Nature 300: 143-149, 1982

3. Reddy EP, Reynolds RK, Santos E, Barbacid M: A point mutation is responsible for the acquisition of transforming properties by the T24 human bladder carcinoma oncogene. Nature 300: 149-152, 1982

4. Taparowsky E, Suard Y, Fasano O, Shimuzu K, Goldfarb M, Wigler A: Activation of the T24 bladder carcinoma transforming gene is linked to a single amino acid change. Nature 300: 762-765, 1982

5. Yuasa Y, Srivastava SK, Dunn CY, Rhim JS, Reddy EP, Aaronson SA: Acquisition of transforming properties by alternative point mutations within c-bas/has human protooncogene. Nature 303: 775-779, 1983

6. Cichutek K, Duesberg PH: Harvey ras genes transform without mutant codons apparently activated by truncation of a $5^{\prime}$ exon (exon -1). Proc Natl Acad Sci USA 83: $2340-2344,1986$
7. Stacey DW, Kung HF: Transformation of NIH 3 T3 cells by microinjection of Ha-ras p21 protein. Nature 310: 508-511, 1984

8. Horan-Hand PH, Thor A, Wunderlich D, Muraro R, Caruso A, Schlom J: Monoclonal antibodies of predefined specificity detect activated ras gene expression in human mammary carcinomas. Proc Natl Acad Sci USA 81: 5227-5231, 1984

9. De Bortoli ME, Abou-Issa H, Haley BE, Cho-Chung YS: Amplified expression of $\mathrm{p} 21$ ras protein in hormone-dependent mammary carcinomas of humans and rodents. Biochem Biophys Res Commun 127: 699-706, 1985

10. Barbacid $M$ : Oncogenes in human cancer and chemically induced animal tumors. Prog Med Virol 32: 86-100, 1985

11. Goldfarb N, Shimuzu K, Perucho M, Wrigler M: Isolation and preliminary characterization of a human transforming gene from T24 bladder carcinoma cell. Nature 296: 404409,1982

12. Krontiris TG, DiMartino NA, Colb M, Parkinson DR: Unique allelic restriction fragments of the human Ha-ras locus in leukocyte and tumor DNAs of cancer patients. Nature 313: 369-374, 1985

13. Thein SL, Oscier DG, Flint J, Wainscoat JS: Ha-ras hypervariable alleles in myelodysplasia. Nature 321: 84-85, 1986

14. Gerhard DS, Dracopoli NC, Bale SJ, Houghton AN, Watkins P, Payne CE, Greene MH, Housman DE: Evidence against $\mathrm{Ha}$-ras-1 involvement in sporadic and familial melanoma. Nature 325: 73-75, 1987

15. Lidereau R, Escot C, Theillet $\mathrm{C}$, Champeme $\mathrm{MH}$, Brunet M, Gest J, Callahan R: High frequency of rare alleles of the human c-Ha-ras 1 proto-oncogene in breast cancer patients. J Natl Cancer Inst 77: 697-701, 1986

16. Theillet $C$, Lidereau R, Escot C. Hutzell $P$, Brunet M, Gest J, Schlom J, Callahan R: Loss of a c-Ha-ras 1 allele and aggressive human primary breast carcinomas. Cancer Res 46: $4776-4781,1986$

17. Koufos A, Hansen MF, Lampkin BC, Workman ML, Copeland NG, Jenkins NA, Cavenee WK: Loss of alleles at loci on human chromosome 11 during genesis of Wilms tumour. Nature 309: 170-172, 1984

18. Bonadonna $G$, Brusamolino E, Valagussa $P$, Rossi A, Brugnatelli L, Brambilla C, DeLena M, Tancini G, Baietta E, Musumeci R, Veronesi U: Combination chemotherapy as an adjuvant treatment in operable breast cancer. $\mathrm{N}$ Engl J Med 294: 406-411, 1976

19. Southern E: Detection of specific sequences among DNA fragments separated by gel electrophoresis. J Mol Biol 98: 503-509, 1975

20. Santos E, Tronick SR, Aaronson SA, Pulciani S, Barbacid $M:$ T24 human bladder carcinoma oncogene is an activated form of the normal human homologue of Balb- and HarveyMSV transforming genes. Nature 298: 343-347, 1982

21. Morton NE: Outline of Genetic Epidemiology. Karger, Basel, 1982

22. Chandler LA, Ghazi H, Jones PA, Boukamp P, Fusening NE: Allele-specific methylation of the human c-Ha-ras-1 
gene. Celi 50: 711-717, 1987

23. Ishii $S$, Nagase T, Imamoto F: Enhancer element of the human Harvey ras proto-oncogene and its polymorphism in human DNA (Abstract). Second Annual Meeting on Oncogenes, Hood College, Frederick (Maryland), 111, 1986 